\title{
A Historical Development of Contrastive ANALYSIS: A RELEVANT REVIEW IN SECOND AND FOREIGN LANGUAGE TEACHING.
}

\author{
Nathalie DJIGUIMKOUDRE \\ Department of Anglophone Studies, Université Joseph KI-ZERBO, Burkina Faso
}

\begin{abstract}
Contrastive analysis (CA) was primarily used in the 1950's as an effective means to address second or foreign language teaching and learning. In this context, it was used to compare pairs of languages, identify similarities and differences in order to predict learning difficulties, with the ultimate goal of addressing them (Fries, 1943; Lado, 1957). Yet, in the 1980's and 1990's the relevance of CA has been disputed. Many studies have pointed out the limit of CA with respect to its weak and strong versions (Oller and Ziahosseiny, 1970), (Wardhaugh, 1970) (Brown, 1989), (Hughes, 1980), (Yang, 1992), and (Whitman and Jackson, 1972). To answer the limits of CA with regards to its weak, strong, and moderate versions, many language teachers used CA with a new approach. Kupferberg and Olshtain (1996), James (1996), and Ruzhekova-Rogozherova (2007). Here, salient contrastive linguistic input (CLI) is presented to learners for an effective noticing. Yet, mere exposition of contrastive linguistic input to learners may not be enough for effective acquisition to occur. Hence, Djiguimkoudre (2020) proposed structured phonemic awareness activities to further strengthen such contrastive salient linguistic input when phonetics and phonology are involved. When grammar is involved, the processing instruction (PI) model of Lee and
\end{abstract}

VanPatten (2003) is recommended since the types of activities that result in PI are believed to incite effective noticing for intake.

\section{KEYWORDS}

Contrastive analysis, phonemic awareness, foreign language, First language, processing instruction

\section{INTRODUCTION}

Contrastive analysis belongs to the field of comparative linguistics which aims at "comparing languages in order to determine potential errors for the ultimate purpose of isolating what needs to be learned and what does not need to be learned in a second-language learning situation" (Gass and Selinker, 2008, p. 96). Here, pairs of languages are compared to identify similarities and differences in order to focus on differences because differences are believed to be learning difficulties (Fries, 1945 and Lado, 1957). Contrastive analysis gave rise to contrastive analysis hypothesis based on three versions, the weak, the strong, and the moderate versions. The weak version of $\mathrm{CAH}$ traces learners error back to their L1 and the strong version supports that differences between the languages compared constitute learning difficulties Wardhaugh (1970), Brown (1987), and Gass and Selinker (2008).

Based on this traditional approach, CA has been prominent in the 1950's in second or foreign language teaching and learning. Hence, many language teachers used contrastive analysis to effectively address learning difficulties. Lado (1957), Lehn and Slager (1959), Sturm (1965), Brown (1987), and Devos et al. (1993). 
However, the effectiveness of CA encountered some limits in the 1990's where some studies have proven it to be irrelevant, and inappropriate. Oller and Ziahosseiny (1970), Hughes (1980), Wardhaugh (1970), and Whitman and Jackson (1972). The strong and weak versions of CA are believed to be too strong and too weak, respectively, to account for learners' errors, hence the advent of the moderate version (Oller and Ziahosseiny, 1970). Following the criticisms towards $\mathrm{CA}$, a group of researchers and language teachers use CA with a new approach. They introduced the concept salient contrastive linguistic input (CLI) which aims at pushing learners to notice the linguistic input exposed to them, Kupferberg and Olshtain (1996), Selinker (1992), Sharwood Smith (1987), Ellis (1995), Robinson (1995), James (1996), and Ruzhekova-Rogozherova (2007).

Djiguimkoudre (2020) goes on to argue that presenting contrastive linguistic input to learners is not enough for effective acquisition to occur. Thus, she suggests that salient linguistic input be reinforced by structured input activities where grammar is involved and phonemic awareness activities where phonology is addressed. These could be objects of other studies.

Hence, the rational of the current study is to mediate between the traditional and new approaches of contrastive analysis. This is done so because the traditional approach of CA has been proven irrelevant vis-à-vis its limits as presented below. The current study considers the limit of CA but states that CA can be used with a new approach whereby the strong, weak, and moderate versions believed to be unrealistic are discarded. Here, salient contrastive linguistic input are introduced and further strengthened by phonemic awareness activities (in phonology) or structured input activities (grammar) to fill the gap of an eventual use CA in the 21st century.

Following the study rational, the objective of the current study is to show that CA can still be used with a different approach for pedagogical purposes. First of all, this study seeks to draw language teachers' attention on the necessity of the new approach of contrastive analysis in second or foreign language teaching. Although the traditional approach of CA, with respect to its strong, weak, and moderate versions are deemed irrelevant, CA is still relevant in language teaching, and could be used differently. In addition, the pedagogical aspect of the current study is to incite language foreign or second language teachers to reconsider the use CA as the starting point of exposure of linguistic input (to learners) or simply as explicit information followed by structured phonemic awareness activities when phonology is involved (Djiguimkoudre, 2020); or processing instruction (PI) based on structured input activities where grammar is used (Lee and VanPatten, 2003).

Saying so, the current study seeks to reexamine the use of contrastive analysis in the 1950's to current. In other terms, this study aims at elaborating the use of CA from 1950's to its criticisms and from its criticisms to the new approaches of CA followed by a contributory discussion. This is done so to draw language teachers' attention on new approaches of CA in second and foreign language teaching and learning. Therefore, the methodology of the current study is much more theoretical consisting of an historical development of CA followed by its new approaches in second and foreign language teaching and learning settings.

\section{Historical BaCkground of Contrastive Analysis (CA)}

CA has been used in the field of SLA in the 1950's, as stated above. It derived from the work of Bloomfield (1933), started in the structuralism era. It was later reinforced by Fries (1945) during which the main goal was to apply the ideas of structural linguistics to language (Lennon 2008). Language as analyzed by structuralist linguists was viewed as a rule- governed system believed to be separable hierarchically into sub-systems whereby each has its own internal structure and pattern (Lennon 2008). Following World War II, language learning and teaching became 
prominent in the United States. With the advent of immigrations to the USA, children of immigrants needed to be taught the foreign language, English. Hence, comparing learners' native and their foreign languages was believed to facilitate acquisition. For instance, Fries, (1945, p.9) stressed that "the most efficient materials are those that are based upon a scientific description of the language to be learned, carefully compared with a parallel description of the native language of the learner." Thus, teaching language based on the contrastive analysis approach whereby learners' first language (L1) features is compared with their foreign language (FL) became indispensable for a successful learning. Being said to have started in the works of Bloomfield (1933) and later on Fries's (1945), Contrastive analysis has been, for the first time, thoroughly developed by Lado (1957). In Linguistics across Cultures, Lado (1957, p.2) supports that a systematic comparison of learners' languages and cultures is crucial for effective language teaching as follows:

We assume that the student who comes in contact with a foreign language will find some features of it quite easy and others extremely difficult. Those elements that are similar to his native language will be simple for him, and those elements that are different will be difficult.

The author adds that what is important in textbooks and teaching materials remains "the comparison of native and foreign language and culture in order to find the hurdles that really have to be surmounted in the teaching", and therefore, textbooks and teaching materials that do not respect the comparative approach will be considered irrelevant (p. 3).

In the same vein, prior to 1960s, contrastive analysis became associated with behaviorist psychology which was another influence on language teaching. Behaviorists argue that language learning is a habit formation. This is supported by Lee and VanPatten, 2003 as they contend that learning a second language is learning new habits to replace the habits of the first language in these terms, "under this framework for learning and teaching, the first language (L1) was seen to interfere with the acquisition of the second language," that is the habits of the L1 impinge upon those of the L2 (p. 9). This is also supported by behaviorist and structuralist as stated in Brown (1980, p.148): "The principal barrier to second language acquisition is the interference of the first language system with the second language system ..." and "... that second language learning basically involved the overcoming of the differences between the two linguistic systems - the native and target languages". Therefore, ccontrastive analysis became prominent in the USA in the 1950s and 1960s and its primary purpose was pedagogical. Hence, some methods are developed to explain why some features of a target language were more difficult to acquire than others.

Contrastive analysis hypothesis $(\mathrm{CAH})$ consists of three versions including, the strong version, the weak version, and the moderate version. The strong and weak versions of contrastive analysis hypothesis (CAH) have been depicted in the works of Wardhaugh (1970), Brown (1987), and Gass and Selinker (2008).

For Wardhaugh the strong version of CAH is the version that claims to predict the difficulties of second language (L2) learning based on contrastive analysis. He continues that the weak version of CAH consists in using "the best linguistic knowledge available [in both learners L1 and L2] ... in order to account for observed difficulties in second language learning" Wardhaugh, (1992, p.136). Here, the emphasis is no longer on the predictive approach of difficulties faced by L2 learners. Rather, the focus is shifted to the explanation of observable errors.

Gass and Selinker (2008, p.8), in the same logic support that the strong version is an a priori version as compared to the weak version which is an a posteriori version as they state: "the a 
priori versus the a posteriori view, the strong versus the weak view, and the predictive versus the explanatory view." The claim of the strong view of CAH is that by comparing two or more languages a "prediction about learning and hence about the success of language- teaching material" can be by made. The weak view, on the other hand, "starts with an analysis of learners' recurrent errors" as it begins "with what learners do and then attempts to account for those errors on the basis of NL- (native language) TL (target language differences)" (Gass and Selinker, 2008, p. 97). The moderate version proposed by Oller and Ziahosseiny (1970, p.186) stipulates that "wherever patterns are minimally distinct in form or meaning in one or more systems, confusion may result". This obviously means that learners may have difficulties to move from one linguistic system to another if the two systems diverge in some ways.

\section{USE OF CONTRASTIVE ANALYSIS IN THE 1960'S to 1990'S}

In the 1960's contrastive analysis was the subject matter of second and foreign language teaching and learning. It became relevant and necessary to design teaching material in second or foreign language teaching settings with respect to the CA approach since many linguists and language teachers proved the necessity to use CA, Lado (1957), Lehn and Slager (1959), Sturm (1965), Brown (1987), and Devos et al. (1993).

Lehn and Slager (1959) demonstrate the significance of CAH as they compared the Egyptian Arabic phonemes to those of American English. They realize that that some learning difficulties of Arabic L1 speakers learning English as L2 are basically English /b/ and /v/ contrast in addition to the absence of the phoneme / ð/ in Arabic that learners substitute by /z/ and /s/.

Sturm addresses the contrastive analysis of some linguistic features of French and English, namely some phonological, morphological, and syntactical differences. The author states that:

The building blocks of French are different from those of English, and practically all mistakes made by a learner of a foreign language are due to his natural inclination to equate the grammatical elements of the native language with those of the foreign language" (Sturm 1965, p. $66)$.

Saying so, second language learners' mistakes derive from their L1 as a result of negative transfer, referred to as the erroneous transfer of the $\mathrm{L} 1$ rules into the $\mathrm{L} 2$. The author predicts that English speakers who are learning French as foreign language are likely to have difficulties producing the following new sounds in French, $/ \mathrm{n} /, / \mathrm{u} /$ as expressed in agneau and rue, respectively, since these sounds do not exist in their native language or first language. He adds that English and French also differ in how the supra-segmental phonemes: pitch, stress, and intonation are structured for French lacks phonemic stress as compared to English where phonemic stress plays an important role. Hence, the author suggests a systematic teaching material that clearly addresses the differences in terms of phonemic stress to solve the problems.

In the same logic, the author's contrastive analysis of the syntactical structure of French and English reveals a difference in the positioning of the direct object pronoun in basic sentence structure. Direct objects in English are generally put after the verb as compared to French where the object pronouns always precede the verb as in the following examples: $\underline{\mathbf{I}}$ see $\underline{\mathbf{h i m}}$ (in English) as opposed to $\underline{\mathbf{J e}} \underline{\mathbf{l e}} \mathbf{\text { vois }}$ in French. Since the first language is believed to influence the second or foreign language, second language learners of French are likely to form ungrammatical sentences, such as: $\underline{\mathbf{J e}} \underline{\mathbf{v o i s}} \underline{\mathbf{l e}}$ or $\underline{\mathbf{J e}}$ vois $\underline{\mathbf{i}}$, because the English language structure and patterns are done so. Therefore, in order to avoid such negative transfer, learners must be taught to reason according to the French syntax (Sturm 1965). 
In the same vein, Devos et al. (1993) use contrastive analysis to solve the object problems between English, French, and Dutch. Being carried at the University of Ghen the goal of the study is to efficiently organize foreign language teaching at secondary school level and to emphasize on the two main foreign languages including French and English. The authors explicitly elaborate "delineation of possible problem areas in foreign language teaching and an extensive pragmatic description of the differences between the native language and the foreign languages" (p. 21-22). This contrastive analysis approach allowed him to notice that the objects' structure in Dutch, English, and French differ considerably.

In Dutch and English, for instance, there are three main objects, including direct object, indirect objects, and prepositional objects whereas in French there are two main objects including, "le complement d'objet direct" and "complement d'objet indirect." (p.22). This analysis makes it apparent that French grammar refers to all objects introduced by prepositions as "complément d'objet indirect". Thus, in French there is no distinction between indirect objects and prepositional objects. Yet, in English and Dutch there is a difference between both indirect objects and prepositional objects. In addition to the object problems involving the three languages as above mentioned, these three languages also differ in the use of transitive and intransitive verbs that is, verbs that require direct objects and verbs that do not require direct objects respectively. The authors stress that the purpose of such contrastive analysis is to provide language teachers with teaching material to consider or exploit in foreign language teaching settings, case of English and French taught at the University of Ghent.

\section{Criticisms Towards CA}

Many studies demonstrate the limit of CAH with regards to its strong and weak versions for what is assumed to be easy for learners is actually not and what is predicted to be difficult is not (Oller and Ziahosseiny, 1970), (Wardhaugh, 1970) and (Whitman and Jackson, 1972). Other studies prove the contrastive analysis approach, namely the predictive and observatory views to be unrealistic. For them, many factors, including psychological, social, and socio- economic factors could affect acquisition, ( Wardhaugh, 1970, and ( Gass and Selinker, 2008), and therefore, basing learners' learning difficulties on the differences between the languages under study is not accurate . Next, considering learners' L1 as the source of their L2 errors is believed to be irrelevant because some studies demonstrate that L2 or FL learners' errors are not necessarily due to their L1( Selinker, 1992). This is supported by learners' interlanguage errors where the features and rules (grammar and vocabulary) produced by the learners are deviant from their L1 and L2 (Nemser, 1971a), ( Selinker, 1992). When learners' errors become deviant from their L1 and L2, they can fail to acquire the linguistic features of their L2. As a result, fossilization could occur (Brown, 1980), (Gass and Selinker, 2008).

In the same vein, Oller and Ziahosseiny (1970) after rejecting the predictive and observatory views of CAH suggest a moderate version. They argue that the strong and the weak versions of $\mathrm{CAH}$ are invalid and incorrect for they consider the former to be too strong and the latter to be too weak, and therefore, cannot effectively and efficiently account for learners' errors. Saying so, they support that $\mathrm{CAH}$ did not consider the extra-linguistic factors of learners. For instance, some psychological factors may affect learners differently. Another flaw of the two versions of contrastive analysis hypothesis $(\mathrm{CAH})$ resides in the fact that students with a similar L1 background always obtain different grades during their learning and testing processes. Hence, the author proposed a moderate version. This version stipulates that, "The categorization of abstract and concrete patterns according to their perceived similarities and differences is the basis for learning; therefore, wherever patterns are minimally distinct in form or meaning in one or more systems, confusion may result" (Oller \& Ziahosseiny, 1970, p. 186). This simply means that 
when two linguistic systems that differ somehow are exposed to learners confusion or interference may occur. Although the moderate version of contrastive analysis hypothesis appeared to be much more plausible, it was later rejected as well (Yang 1992).

Hughes (1980), in the same respect, depicts the downsides of CAH since it fails to predict learning difficulty (Cited in Yang, 1992, p. 139-140). He also criticizes the fact that CAH is unable to predict errors that learners could have avoided when they have followed the pattern of their L1 when he states:

(1) We do not have the descriptions of the languages that we need.

(2) If we had the right descriptions, it will not still be obvious as to what we should compare them with what.

(3) If we did have a satisfactory objective measure of similarity or difference.

(4) If we did have a satisfactory measure of difference, it is unclear how we would predict degrees of difficulty with any accuracy (p. 139-140).

This is further supported by Wardhaugh (1970). For him the predictive view, by extension the strong version of CAH is "unrealistic and impracticable" (p. 125).

Whitman and Jackson (1972, p. 40) also perceive the flaws of CAH. After testing 2500 L1 Japanese learners of English as foreign language in order to assess predicted levels of difficulty on grammar, the authors realized that "what was predicted to be easier was harder and vice versa". These findings trigger them to conclude that contrastive analysis "is inadequate, theoretically and practically, to predict the interference problems of a language learner" (p.40).

However, despite the ongoing criticism towards contrastive analysis, it has still been used today. Djiguimkoudre (2020) argues that if CA is still used today by language teachers to predict and address learning difficulties, therefore, there is something relevant and valid about it that we should not ignore. Yet, this matter should be handled with care to cope with the current developmental approaches of CA.

\section{Different APPRoACh OF CONTRASTIVE Analysis}

Kupferberg and Olshtain (1996) demonstrate that contrastive analysis could be used for a "specific purpose which is compatible with recent developments in the field" (p.150). The authors, in this study, reveal that salient contrastive linguistic input facilitates noticing since learners are likely to attend to meaning and some aspects of the linguistic form they are exposed to. As stated in Kupferberg and Olshtain (1996), some former studies such as, Selinker (1992), Sharwood Smith (1987), Ellis (1995), and Robinson (1995) in the related research have proven that linguistic input salience paves the way to effective L2 acquisition for learners who are exposed to explicit input could understand the grammatical rules they are exposed to. Kupferberg and Olshtain (1996) go on to emphasize on the salient contrastive linguistic input and its effect on L2 learners. For them, "Exposure to salient linguistic input may trigger explicit learning, a conscious operation" (p.149). They add that, "If learners attend to the input, they may notice a specific linguistic feature in it" (149). By saying so, during the exposure of the L2 linguistic form learners are susceptible to notice a particular feature that they take in (intake). Noticing "means detecting and then rehearsing the feature in short term memory" (Robinson 1995 cited in Kupferberg and Olshtain, 1996, p. 149) before the feature is stored in the learner's long-term memory. Once the input is stored in the learners' long-term memory, their ability to produce such input is called intake as supported by R. Schmidt (1990) cited in Kupferberg and Olshtain (1996, p. 150) as follows: "Input which is attended to and noticed becomes intake." 
This article focuses on contrastive linguistic input (CLI) followed by a test to assess its effect on the acquisition of difficult grammatical structures in English by native speaker of Hebrew. The premise of this article is that salient contrastive linguistic input via input enhancement may incite L2 language awareness or noticing and therefore, an effective acquisition of the grammatical features of the L2. Input enhancement helps raise L2 awareness of some features the language being learnt. As illustrated in this article, the term " 'input enhancement' was proposed as a safer alternative to 'consciousness- raising' since consciousness is a polysemous construct which focuses on the learner's inner processes, to which the teacher or the researcher have [has] no direct access" (Schmidt, 1994, p. 150). Sharwood Smith (1993) even uses 'input enhancement' and 'induced input salience interchangeably'.

To verify this premise, as above mentioned, the authors conduct a study that involve the following processes. The participants, 137 year-old native speakers of Hebrew, have been randomly divided into two groups, including the experimental group (70 students) and the control group (67 students). These students have five-year background information of English although the subjects had not learned the structures in class before the beginning of the treatment. Data are collected based on controlled recognition and production tasks administered in a pre-test (time 1) and two post-tests (time 2 and time3). Time 2 measurement was administered when the experimental intervention was completed, and time 3 measurement three months after time 2 . Measurement tasks which comprised recognition and production were used. Contrastive features were statements that clearly summarized the inter-lingual differences. There are two compound noun $(\mathrm{CN})$ contrastive features in Hebrew: the head modifier ordering, and the fact that the modifier is singular. The reduced restrictive relative clause (RRRC) contrastive feature focused on the simultaneous deletions (of the relative pronoun and the verb be).

The procedure of the study as clearly summarized in the tale below yields some outstanding results.

Table 1. Type and time allotment of instruction given to the experimental and control groups

\begin{tabular}{|c|c|c|}
\hline \multirow{2}{*}{ Instruction } & \multicolumn{2}{|c|}{ Time (minutes) } \\
\cline { 2 - 3 } & Experimental & Control \\
\hline (1) Presentation (inductive) & About 15 & About 15 \\
\hline (2) CLI & About 5 & \\
\hline (3) Recognition tasks and CLI & About 5 & \\
\hline (4) Communicative tasks & About 25 & About 35 \\
\hline (5) Feedback Affective and content-oriented & About 12 & About 15 \\
\hline CLI & About 3 & \\
\hline
\end{tabular}

The ANOVA method is used to verify the hypothesis according to which contrastive input facilitates the acquisition of the two grammatical structures for speakers of Hebrew. The final results show that Hebrew speaking learners of English benefited from explicit exposure to CLI and recognition tasks which facilitated the subsequent acquisition of L2 grammatical forms. The experimental group achieves significantly better results on all tasks in comparison with the control group, who learnt the same structures implicitly from comprehensible input only. Although the control group improved in times 2 and 3, it is obvious that CLI helped Hebrew speakers of English attend the difficult grammatical features. Therefore, "CLI can be viewed as a foreign language acquisition 'facilitator' of such difficult grammatical forms" (160).

In the same vein, James (1996) uses a new direction of contrastive analysis. In this article, the author used contrastive analysis as contributing to language awareness. Before explaining how this is made possible, he distinguished awareness from consciousness. For the author, "in 
addition to LA [language awareness] there is consciousness of language" leading to "consciousness- raising" (p.139) whereas "language awareness" refers to the "possession of metacognitions about language in general, some bit of language, or a particular language over which one already has skilled control and a coherent set of intuitions" (p.140). By saying so, instead of viewing consciousness and awareness as synonyms it is worth noticing the difference; and viewing them as complementary is crucial in language acquisition. The author adds that CR is for language learners who are not yet "in command of these formal repertoires and consistent intuitions" (141). LA and CR have been later on classified with regards to mother tongue (MT) and foreign language (FL) learning. The former is used in the context of mother tongue learning and the latter for FL acquisition. This dichotomy is plausible in the sense that mother tongue learners already have a conscious knowledge of the language but need to be aware of some particular structures in the language whereas foreign language learners need to first of all have a conscious understanding of the language before they can attend meaning of some features of that language.

The author quoted the view of Rutherford and Sharwood Smith (1985) of CR in the following terms: "Rutherford's and Sharwood Smith (1985, p.274) define CR as 'the deliberate attempt to draw the learner's attention specifically to the formal properties of the target language"" (p.141). He clarifies that learners' attention should not be drawn on all properties of the target languages but rather on those learners have difficulties to learn. Thus, this aspect of consciousness raising is similar to contrastive linguistic input salience for it consists on drawing learners' attention on some divergent properties of the L2 as well, and therefore, could help students attend meaning of those aspects of the L2.

In the same article, the author stresses that LA and CR involve noticing "(Schmidt, 1990, p. 144) something about a language (NL or FL) that one had not noticed earlier, often (as teachers know too well) despite having had practice opportunities..." (p.143). If the learner has not noticed some particular aspects of the TL they are not available for intake. To address the issue of what makes noticing possible among TL learners is expressed by the author when he says "As to what makes an aspect of the foreign language (FL) noticeable, Schmidt suggests frequency, functionality," and, most importantly, he says "I think is the perceptual salience" (p.143). He adds that "salience is specially pronounced if the learner has high LA of the corresponding MT item" (p.143). He further develops the bilinguals' awareness of language to explain the effect of the contact of two languages in the bilingual brain with respect to the cognitive and metacognition consequences. The findings show that bilinguals attempt to resolve the interference between his languages as follow:

(1) He indulges in language analysis, refining his awareness of the different ways in which each language 'processes a given paradigm'...

(2) Bilinguals strive very hard to develop a mechanics to keep their two languages apart...

(3) Bilinguals are more sensitive to feedback than monolinguals, which makes open to correction... (p. 144).

The author also depicts an aspect of traditional CA that was taken into account in this study. For him the traditional CA was done by applied linguists outside of classroom "not by learners in classrooms," and by doing so, "the damage expected from MT interference in FL learning" was ignored (p.145). Now the tendency has changed since the modern CA "took a look on a cognitive complexion, where the learner is more in charge of his own learning destiny..." (p.145). Being inspired by the new version of CA, this present study involved L2 learners in a classroom setting. 
To question how to implement target CR and LA of the MT is also discussed in the article. For the author, it sounds accurate to start with what is common in both languages before dealing with the contrast later as he referred to Poldauf (1995) in his work as follows: " Poldauf $(1995$, p. 6) suggests we should 'proceed from what is common in the two languages 'and shift the focus to contrast later" (p.145). Although this strategy sounds appealing, I will go along with both similarities and differences in my research because it is not obvious that similarities and difficulties will necessarily cause ease and learning difficulty, respectively. Sometimes similarities in both languages can cause a learning difficulty as demonstrated Oller and Ziahousseiny (1970).

This article also demonstrates that CA is no longer predictive but rather a tool used to contrast the linguistic properties of two languages with the aim to help L2 learners attend to the difficult structures in their L2 for effective acquisition. Yet, so far, the author does not develop a strategy of FL leaning setting that involves the noticing of contrastive salience. In our study, we use contrastive analysis as an efficient means to incite noticing of the divergent phonemes and phonological rules in both languages.

Next, Diallo et al. (2009) use a different approach of contrastive analysis in language teaching that they refer to as "a contrastive description and a converging didactics" (p.3). This textbook focuses on the acquisition of a second language with regards to the cultural and linguistic history of the learner. According to this textbook, it is likely that starting with the grammatical rules of learners' first language (L1), generally used as the language of social communication and interaction, would allow them to easily acquire their second language (L2). In this article, Fulfulde is the L1 and French the L2. Fulfulde is a language commonly spoken in sub-Saharan Africa. According to the authors, the goal of this study is to provide teachers with some teaching materials to systematize the grammatical rules of the L1 and the L2 for a double perspective interest: a contrastive description and a converging didactics

(Diallo et al., 2009, p.3). They continue that another beneficiary target of the grammatical rules would be the Pularophone students (Fulfulde native speakers) of elementary school in the sense that by consolidating their L1 grammar rules, they are at the same time involved in a parallel and formal learning of their L2, French.

In this study, the teaching material is organized in files as follows: the alphabet of similar vowels and consonants in both Fulfulde and French, the alphabet of similar vowels and consonants but with divergent pronunciations, the alphabet of dissimilar sounds in both languages, and the combination of many vowels for the production of one sound, respectively. Based on this comparative study that involves the alphabet of both L1(Fulfulde) and L2 (French) it results, from the first file, that Fulfulde and French have fourteen (14) consonants and vowels that are similar in spelling and pronunciation. They are written as follows: $\mathbf{a}, \mathbf{b}, \mathbf{d}, \mathbf{f}, \mathbf{i}, \mathbf{k}, \mathbf{l}, \mathbf{m}, \mathbf{n}, \mathbf{o}, \mathbf{p}, \mathbf{r}$, $\mathbf{t}$, and $\mathbf{w}$. Some examples are used in the two languages to illustrate the similarities. In the second file, the authors distinguish eight (8) alphabet letters, $\mathbf{c}, \mathbf{e}, \mathbf{g}, \mathbf{h}, \mathbf{j}, \mathbf{s}, \mathbf{u}, \mathbf{y}$, which are similar in spelling but different in pronunciation. In the next file, the following vowels and consonants are specific to each language. For instance, the following sounds: $\mathbf{6}, \boldsymbol{d}, \boldsymbol{y}, \boldsymbol{\eta}$ and a are unique to Fulfulde whereas $\mathbf{v}, \mathbf{x}, \mathbf{z}$ and $\mathbf{q}$ belong to French. The last file concerns the combination of many vowels which provide one sound in French. This process that is unique to the French language does not exist in Fulfulde.

More interestingly, the authors use detailed examples for the entire alphabet in the two languages with attention to their similarities and divergences as well as some clear explanation, practice exercises, and remarks on each file. By doing so, students will be able to notice and understand the similar and dissimilar vowels and consonants. 


\section{CONTRibutory Discussion}

It is apparent that the traditional approach of contrastive analysis (CA) with respect to its weak, strong, and moderate version are nowadays considered to be outdated. This explains why James (1996), Kupferberg and Olshtain (1996), and Diallo et al. (2009) use CA with a new approach as they introduce salient contrastive linguistic input to facilitate noticing. The current study supports this new approach of CA, yet it argues that salient contrastive linguistic input only is not enough for effective and efficient acquisition to occur. Therefore, these contrastive linguistic inputs can further be reinforced by series of structured input activities to efficiently and effectively facilitate learning.

Djiguimkoudre (2020), for instance, after using the new approach of CA to comparing the phonemes of Moore as first language (L1), French as an intermediate language (L int), and English as foreign language (FL) uses structured phonemic awareness activities to help learners better acquire the phonemes of their foreign language, English. The author assumes that even though predicting learning difficulties is considered nowadays to be relevant in second and foreign language teaching and learning, CA remains at least crucial to compare the linguistic systems of the languages under study to allow learners to better notice the differences and similarities of these languages. This constitutes, for the author, the starting point of learning. After providing learners with the contrastive analysis of the three languages, as above mentioned, the author designs structured phonemic awareness activities slightly based on Lee and VanPatten (2003) structured input activities model. The structured phonemic awareness activities aims at pushing learners better identify, represent, and manipulate the phonemes of their foreign language, here English.

Phonemic awareness is defined as "the ability to explicitly manipulate speech segments at the phoneme level" Cunningham (1990, p. 429). Common phonemic awareness activities, previously developed, include Phonemic awareness activities which consist of

blending, segmentation, identification, and discrimination (Adams, 1990), (Cunningham, 1990), Szabo (2010), (Jensen, 2011), and (Fielding-Barnsley, 1997). Yet, Djiguimkoudre (2020) bases her phonemic awareness activities mainly on identification, representation, and manipulation of phonemes with phonemes being defined as the smallest distinctive units of a speech sounds. They are represented as follows: /p/, /d/, /t/, /i/, /æ/ and so on (Language Files, 2007). The phonemes of the English language are divided into consonant and vowel sounds as represented in the tables below

Table 2. Phonemic chart of English consonants by Dauer (1993), and Language Files (2007).

\begin{tabular}{|c|c|c|c|c|c|c|c|c|}
\hline Manner & Voicing & \multicolumn{7}{|c|}{ Place of articulation } \\
\hline \multirow[b]{3}{*}{ Stops } & Voiced & Bilabial & labiodental & interdental & alveolar & palatal & velar & glottal \\
\hline & & $\mathrm{b}$ & & & $\mathrm{d}$ & & $g$ & \\
\hline & Voiceless & $\mathrm{P}$ & & & $\mathrm{t}$ & & $\mathrm{k}$ & $?$ \\
\hline \multirow[t]{2}{*}{ Fricatives } & Voiced & & $\mathrm{V}$ & д & $\mathrm{s}$ & 3 & & \\
\hline & Voiceless & & $\mathrm{F}$ & $\theta$ & $\mathrm{z}$ & $\int$ & & $\mathrm{h}$ \\
\hline \multirow[t]{2}{*}{ Affricates } & Voiced & & & & & ds & & \\
\hline & Voiceless & & & & & t & & \\
\hline Flap & & & & & $\mathrm{s}$ & & & \\
\hline Nasal & Voiced & $\mathrm{m}$ & & & $\mathrm{n}$ & & & $\mathrm{y}$ \\
\hline Lateral & Voiced & & & & 1 & & & \\
\hline Rhotic & Voiced & & & & $\mathrm{I}$ & & & \\
\hline Glides & Voiced & $\mathrm{W}$ & & & & $\mathrm{j}$ & $\mathrm{W}$ & \\
\hline
\end{tabular}


Table 3. Phonemic chart of English vowels

\begin{tabular}{|c|c|c|c|c|c|}
\hline & Front & Central & back & roundedness & tenseness \\
\hline \multirow[t]{2}{*}{ high } & $\mathrm{i}$ & & $\mathrm{u}$ & & Tense \\
\hline & I & & U & & Lax \\
\hline \multirow[t]{2}{*}{ Mid } & e-tense & $\partial$ & o & rounded & Lax \\
\hline & $\varepsilon$ & $\Lambda$ & 0 & & Lax \\
\hline Low & $æ$ & & $a$ & unrounded & Lax \\
\hline
\end{tabular}

Djiguimkoudre (2020)'s phonemic awareness activities are structured as follows:

\section{Activity 1: Listening to identify phonemes}

Here, learners hear the instructor read a passage. They write the passage down in their exam sheet, where the instructor already provided them with a number of phonemes. The task here is to ask students to identify and represent the given phonemes in the text they wrote.

\section{Activity 2: Reading to identify phonemes}

Students are given a text, in which some letters of the English alphabet are underlined. The assignment here is to have students provide the phonemic representation of the underlined letters.

\section{Activity 3: Matching}

In this activity, students are given a passage where letters are underlined. In addition, they are given many phonemes (some of which are not represented in the passage) to match with the underlined alphabet letters. This is done so to push learners to better choose and process the correct phoneme.

\section{Activity 4: Filling in the blank}

Here, learners are asked to fill the blank with the phonemes provided to them to convey meaningful words. This activity aims at pushing learners to derive meaning at two levels, phoneme level, and word level.

\section{Activity 5: transcription}

\section{Turning a transcription into a text}

Students are asked to turn a transcribed passage into a normal text. The purpose of this activity is to push learners to move from the knowledge of individual phonemes into the knowledge of combined phonemes in sentences and texts by extension. We assume that since learners have been pushed to attend to the phonemes of their target language, they could derive meaning from combined phonemes as well for the purpose of structured input activities is not to only have learners master the phonemes but to also use them communicatively (in speech, in text...)

\section{Transcribing basic words in English}

Learners have been introduced to English in high school and they are currently taking their first semester courses at the university level at the Department of Anglophone Studies. It is obvious 
that they have been introduced to some basic English words. At this level, we want them to transcribe the words by using the phonemes exposed to them

Following the description of the PA activities, the PA activities are stated below

\section{Listening to identify phonemes}

Students are asked to write down the conversation as you hear it and underline the following phonemes from the first sentence as represented below:

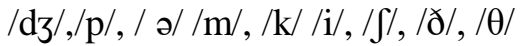

The instructor read the following passage:

People from different parts of the country speak with accents that show which region they come from. An accent includes minor differences in vocabulary, grammar, and specially pronunciation. After this step, they are asked the following questions:

a. In the second sentence, underline 5 phonemes and then represent them,

b. What is the passage about?

\section{Reading for phonemes' identification}

Learning to speak a foreign language fluently and without an accent isn't easy. In most educational systems, students spend many years studying grammatical rules, but they don't get much of a chance to speak. Arriving in a new country can be a frustrating experience. Although

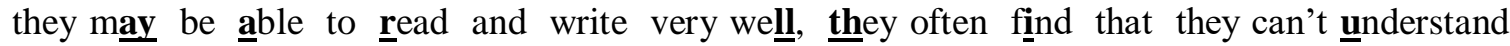
what people say to them. English is especially difficult because the pronunciation of words is not clearly shown by how they are written. But the major problem is being able to listen, $\underline{\text { think, and }}$ respond in another language at a natural speed. This takes time and practice.

The passage is taken from: "Accurate English: A complete Course in Pronunciation" by (Dauer 1993: 6).

In the passage, some sounds are underlined and put in bold to incite students to pay attention to those sounds After that, students are asked to represent the phonemes of the underlined sounds followed by the production of each.

\section{Matching 1}

Match the different phonemes below with the three languages and providing examples for each, where you underline the phoneme in each Example. The say phoneme may belong to the three languages.

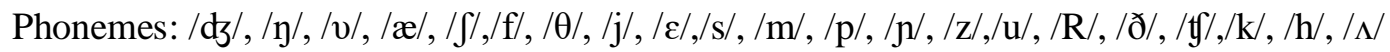

Ex: the phoneme / $/$ / belongs to both English and French

English $=\underline{\text { show; }}$ French $=\underline{\text { chat }}$ 


\section{Matching 2}

Match the following phonemes below with the underlined letters.

1) Many students work hard to pass their exams even though some do nót do so.

2) During the trial, the judge declared the convicted guilty.

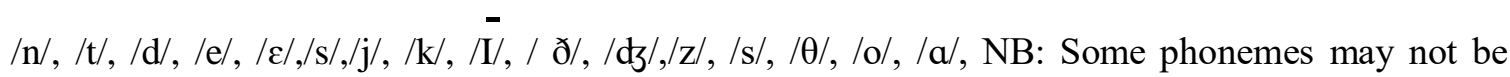
used.

NB: Some phonemes may not be used.

Here, student will be asked to match the missing phonemes from the list below to convey meaning. Some phonemes may not be used.

\section{II.1.5. Complete the blank with the missing phoneme to convey meaning}

1), /k-t/, 2)/ li--'gw--sti-s/, 3 /lu --/, 4 /--ə'lai/, 5) /fl-d/

a) $/ \mathrm{k} /$; b)/z/; c) $/ \mathrm{I} /$, d) $/ \mathfrak{x} /$; e)/3/, f) $/ \mathrm{d} z /$, g) $/ \mathrm{y} /$, h) $/ \mathrm{u} /, / \mathrm{s} /, / \mathrm{N} /$

\section{II.1.6. Transcribe the following words and expression phonemically}

phonemes, studies, teacher, work, students, at the library, women, education, this church, her mother, the jury, thinking, the child.

\section{II.1.7. Turn the following transcription into a text.}

1) /'l3rnıy tu spik ə 'forən 'læygwids 'fluəntli ænd wi' $\theta$ aot ən 'æksent 'izənt 'izi/

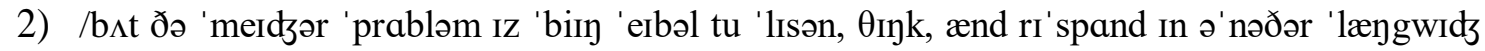
æt ə 'næfərəl spid. ðIs terks taIm ænd 'præktəs/

\section{II.1.8. Write the following words as you heard them and then transcribe them:}

Nice, a book, at the bookstore, the boy hit the ball, the rain made her wet, what is this? I love it, be careful, student, study.

Yet, the phonemic awareness activities are limited to phonology, namely the segmental features. If grammar is involved, the author suggests that the grammar points be compared in order to identify the differences and similarities which could also be further reinforced by VanPatten and Cadierno (1993), and Lee and VanPatten (2003) processing instruction teaching model, based on structured input activities as follows:

- Supplying Information

- Surveys

- Matching

- Binary Options (True/False, Logical/Illogical, Normal/Strange, etc.)

- Ordering/Ranking (Lee \&VanPatten, 2003). 
In fact, processing instruction (PI) teaching model, which is based on structured input (SI) activities, has been recently used in the field of second and foreign language learning believed to be beneficial in helping learners acquire the grammar points of their foreign and second languages. But what is processing instruction?

Processing instruction (PI) is generally defined as the way learners process or manipulate the input exposed to them. In other words, PI is concerned with input processing, how "learners initially perceive and process linguistic data in the language they hear" (Lee and VanPatten , 2003 , p. 137). Input processing is a psycholinguistic strategy whereby learners derive intake from input, with input being referred to as the linguistic dada exposed to learners, and intake as the linguistic data from the input that the learner assimilates and keeps in his/her memory. It has been recently used in the field of foreign and second language learning as an effective teaching method to the detriment of traditional teaching/instruction. Processing instruction (PI) originated from the work of (VanPatten \& Cadierno, 1993). Based on structured input activities, PI aims at providing an appropriate teaching method in foreign language teaching. Lee and VanPatten (2003) further demonstrate the necessity of PI in second and foreign language teaching. The PA teaching model is represented in the figure below:

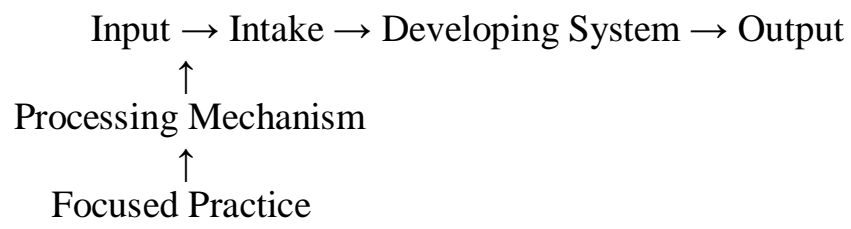

Figure 1. Processing-oriented instruction

This figure simply means that, in processing instruction, learners are pushed through structured input activities to attend to the linguistic data exposed to them that will obviously make it easier for them to successfully internalize the data, and produce output when needed. Below are some structured input activities elaborated in Lee and VanPatten (2003, p. 143)

Activity A. Listening for Time Reference

Listen to each sentence. Indicate whether the action occurred last week or is part of a set of actions oriented toward the present.

\section{(SENTENCES READ BY INSTRUCTOR OR HEARD ON TAPE)}

1. John talked on the phone

2. Mary helped her mother on the phone

3. Robert studies for two hours

4. Sam watched TV

5. Lori visits her parents

Learners might then be given sentences and told to match each to a particular adverbial.

\section{Activity B. Matching}

Once again, listen to each sentence. Select the appropriate time-related adverbials that can be added to the sentences you hear. 
MODEL: (you hear) John deposited money in the bank. (you select from)
a. last Monday
b. right now
c. later this week (you say) Last Monday

Further activities could be developed that involve what the learners themselves did or didn't do at a particular time.

For more information about processing instruction and structured input activities see VanPatten and Cadierno (1993), VanPatten and Oikkenon (1996), and Lee and VanPatten (2003).

\section{Conclusion}

Contrastive analysis has been used in the 1960's for pedagogical purposes. It is believed to be necessary in second or foreign language teaching (Lado, 1957). However, in the 1970's many linguists and language teachers have proven the irrelevance of CA in SLA (Oller and Ziahosseiny 1970), Hughes (1980), Wardhaugh (1970), and Whitman and Jackson (1072). This gave rise to a new approach of $\mathrm{CA}$ in second and foreign language teaching. Instead of predicting learning difficulties, contrastive linguistic input (CLI) is presented to learners to draw their attention on the linguistic input exposed to them Kupferberg and Olshtain (1996), James (1996). Some language teachers go on to compare learners' first language (L1) and second language (L2) in order to teach them their L2 through the medium of their L1 (Diallo et al., 2009). Therefore language teachers are recommended to consider the new approaches of CA in their teaching settings for a better teaching and acquisition of linguistic items presented to learners. These new approaches could be further reinforced by structured PA activities when phonology is involved as suggested by Djiguimkoudre (2020). When grammar is involved, Lee and VanPatten (2003) processing instruction teaching model is necessary. More novel teaching approaches in second and foreign language teaching and learning settings are necessary to continue addressing and identifying effective teaching methods.

\section{REFERENCES}

[1] Adams, M. J. 1990. Beginning to Read: Thinking and Learning about Print. Cambridge, MA: MIT Press.

[2] Bloomfield, L. (1933). Language. Rinehart and Winston (Eds.), New York: Holt

[3] Brown, H. D., (1987). Principles of Language Learning and Teaching. Englewood Cliffs, N. J/ Prentice-Hall.

[4] Cunningham, A. E. (1990). Explicit versus Implicit Instruction in Phonemic Awareness. Journal of Experimental Child Psychology. 50. 429-444.

[5] Dauer, R.M. (1993). Accurate English: A Complete Course in Pronunciation. Massachussett: Prentice Hall

[6] Diallo, I., Diallo, M. S., Gnalibouly, B., and Wane, M. (2009). Bi-Grammaire : Fulfuldé/ PulaarFrançais. Burkina Faso : Organisation Internationale de la Francophonie.www.Lewebpedagogic.com/oif.

[7] Djiguimkoudre, N. (2020). Teaching English phonemes to Moore EFL students using phonemic awareness activities: A contrastive analysis approach. Unpublished Doctoral Dissertation. Université Joseph Ki-Zerbo, Burkina Faso.

[8] Djiguimkoudre, N. (2020). Contrastive analysis: A valid concept in the 21st century? Education Research Journal, 10, 298-304.

[9] Ellis, N.C. (1995). Consciousness in second language acquisition: A review of field studies and laboratory experiments. Language Awareness, 4, 123-46. 
[10] Fielding-Barnsley, R. (1997). Explicit instruction in decoding benefits children high in phonemic awareness and alphabet knowledge. Sci. Stud. Read. 1, 45-63. doi:10.1207/s1532799xssr0101

[11] Fries, C. (1945). Teaching and Learning English as a Foreign Language. Ed. Ann Arbor. Univ of Michigan Press.

[12] Gass, M., and Selinker, L., (2008). Reexamining the role of explicit information in Processing Instruction. Studies in Second Language Acquisition, 30, 277-305.

[13] Gast, V. (2012). Contrastive Linguistics: Theories and methods. Dictionaries of Linguistics and Communication Science: Linguistic theory and methodology. Berlin: Mouton de Gruyte

[14] Hughes, A. (1980). Problem in Contrastive Analysis and Error Analysis. ED 192573.

[15] James, C. (1996). A cross-linguistic approach to language awareness. Language Awareness, 5(3), 138-148.

[16] Jensen, J. (2011). Phoneme acquisition: infants and second language learners. The Language Teacher, 35(6), 24-28.

[17] Kupferberg, I., and Olstain, E. (1996). Explicit Contrastive Instruction Facilitates the Acquisition of difficult L2 Forms. Language Awareness, 5, (3\&4), 149-165.

[18] Lado, R. (1957). Language across Cultures. Ann Arbor: Univ of Michigan Press.

[19] Lee, J. F., and VanPatten, B. (2003). Making Communicative Language Teaching Happen. New York: McGraw-Hill Companies, Inc.

[20] Lehn, W., and Slager W. R., (1959). A contrastive analysis of Egyptian Arabic and American English: The segmental phonemes. Language Learning, 9,1-2.

[21] Lennon, P., From S. Gramley., V. Gramley (eds). (2008). Bielefeld Introduction to Applied Linguistics. Bielefeld: Aisthesis, pp. 51-60

[22] Oller, J. W., and Ziahosseiny S. M., (1970). The Contrastive Analysis and Spelling Errors. Language Learning, 20.

[23] Poldauf, I. (1995). Language awareness. Language Awareness, 4,1, 3-14

[24] Robinson, P. (1995). Attention, memory and the noticing hypothesis. Language Learning Linguistics, $11,129-158$.

[25] Rutherford, W. E., and Sharwood Smith, M. (1985). Consciousness and universal grammar. Applied Linguistics, 6, 3, 274-83.

[26] Ruzhekova-Rogozherova, B. (2007). Contrastive analysis (French-English) in teaching English preterit and perfect through technical texts. E-magazine liter-note, 10, 95.

[27] Selinker, L. (1992). Rediscovering Interlanguage. London: Longman.

[28] Sharwood Smith, M. (1987). Notions and functions in a contrastive pedagogical grammar. In W. Rutheford and M. Sharwood Smith (eds). Grammar and Second Language Teaching: A Book of Readings Rowley, MA: Newbury House. (pp. 156-70).

[29] Sturm, V. J. (1965). Applied French linguistics. Virginia Modern Foreign Language Association. 3 (21), 66-68

[30] Szabo, S. (2010). Older children need phonemic awareness instruction, too. TESOL Journal 11, 130141.

[31] VanPatten, B., and Cadierno, C. (1993). Input processing and second language acquisition: A role for instruction. The Modern Language Journal, 77, 45-57.

[32] VanPatten, B., and Oikkenon, S. (1996). Explanation versus structured input in processing instruction. Studies in Second Language Acquisition, 18, 495-510.

[33] Wardhaugh, R. (1970). The contrastive analysis hypothesis. TESOL quarterly 4.

[34] Whitman, R., and Jackson, K. (1972). The unpredictability of contrastive analysis. Language Learning, 22, 29-41.

[35] Yang, B. (1992). A Review of Contrastive Analysis Hypothesis, 2, 133-149. 